\title{
VISÕES DE LEITURA E CONCEPÇÕES QUE FUNDAMENTAM OS DOCUMENTOS OFICIAIS DE ENSINO E APRENDIZAGEM DE LÍNGUA ESTRANGEIRA**
}

\section{READING VIEWS AND CONCEPTS UNDERLYING THE OFFICIAL DOCUMENTS ON SECOND LANGUAGE TEACHING AND LEARNING}

\section{Juliana Santana Cavallari ${ }^{\star}$}

\section{RESUMO}

O objetivo deste artigo é abordar as visões de leitura e as concepções que embasam o processo de ensino e aprendizagem de língua estrangeira (LE) na escola regular de acordo com os documentos oficiais elaborados para orientação da prática docente, a saber: os Parâmetros Curriculares Nacionais de Língua Estrangeira do Ensino Fundamental (PCNLE, 1998), a Proposta Curricular do Estado de São Paulo, voltada para o ensino de Língua Estrangeira Moderna (MEC/SEE, 2008 a), e o Caderno do Professor, destinado para os professores de inglês do ensino médio (SEE, 2008 b). Para tanto, após percorrer as diferentes visões de leitura, com base nos estudos de Coracini $(1995,2000,2001)$ e Leffa (1996), foram retomados alguns trechos dos documentos em questão, de modo a observarmos como as propostas e orientações pedagógicas se configuram discursivamente e se são ou não condizentes com a orientação teórica que o material analisado acredita adotar. Em última instância, este estudo pretende refletir sobre os efeitos das concepções de leitura, sujeito e linguagem na constituição e formação do sujeito-aluno leitor de LE. Do ponto de vista teórico, o presente artigo se baliza pela perspectiva discursiva.

Palavras-chave: leitura em língua estrangeira; documentos oficiais; perspectiva discursiva.

\section{ABSTRACT}

The purpose of this study is to point out the reading views and the concepts underlying the second language teaching and learning process at regular schools, according to official documents which have been developed to guide the teaching practice, such as: the National Curriculum Parameters (1998), São Paulo's Curriculum Proposal, concerning the teaching of Modern Languages (MEC/SEE, 2008 a), as well as the manual addressed to

\footnotetext{
*UNIVAS, Pouso Alegre (MG), Brasil. judu77@hotmail.com

** Este artigo resultou de um trabalho apresentado no VII Seminário de Pesquisas em Linguística Aplicada (SePLA), da UNITAU, realizado em maio de 2011.
} 
high school English teachers (SEE, 2008 b). In order to achieve our purpose, after going through different reading views, based on Coracini's $(1995,2000,2001)$ and Leffa's $(1996)$ studies, some excerpts of the documents were revisited, so that we could observe how the pedagogical orientations are discursively designed and whether they are coherent with the theory that the material analyzed claims to adopt. Finally, this paper aims at thinking about the effects of some concepts, such as: reading, subject and language concepts upon the education of second language readers. From the theoretical point of view, the current study is based on the discursive perspective.

Keywords: second language reading, official documents; discursive perspective.

\section{INTRODUÇÃO}

O objetivo deste artigo é abordar as visões de leitura e as abordagens que deveriam embasar o processo de ensino e aprendizagem de língua estrangeira (LE), na escola regular, de acordo com os documentos oficiais elaborados para orientação da prática docente, a saber: os Parâmetros Curriculares Nacionais de Língua Estrangeira do Ensino Fundamental (PCN-LE, 1998), a Proposta Curricular do Estado de São Paulo, voltada para o ensino de Língua Estrangeira Moderna (MEC/ SEE, 2008 a), e o Caderno do Professor, destinado aos professores de inglês do ensino médio (SEE, 2008 b) e que também se pauta nos documentos anteriormente citados.

Tendo em vista que, de acordo com os documentos oficiais que versam sobre o ensino de LE na escola regular, o foco da prática docente está na formação da competência de leitura e de escrita, a partir do trabalho realizado com textos escritos, faz-se necessário abordarmos as diferentes visões que direcionam o processo de leitura, para, posteriormente, salientarmos a visão e as abordagens que são privilegiadas nos documentos analisados. Para tanto, após percorrermos as diferentes visões de leitura, com base nos estudos de Coracini $(1995,2000$, 2001) e Leffa (1996), retomaremos alguns trechos dos documentos em questão, de modo a observarmos como as propostas e orientações pedagógicas se configuram discursivamente e se são ou não condizentes com a orientação teórica sociointeracionista que o material analisado afirma adotar.

Ao longo das análises empreendidas, pretendemos contrapor a visão de leitura como processo discursivo à visão 'prescrita' nos/pelos documentos, enfatizando algumas especificidades das diferentes visões, para, em última instância, (re)pensar sobre os efeitos dessas concepções na constituição e formação do sujeito-aluno leitor de LE. 
Do ponto de vista teórico, o presente artigo se baliza pela perspectiva discursiva, uma vez que tenta resgatar, no material analisado, o modo como os enunciados formulados produzem efeitos de sentido e de verdade. É significativo destacarmos que a abordagem discursiva procura ancorar a análise dos registros na materialidade linguística, 'desnudando' os aspectos históricos, sociais e ideológicos que atuam na constituição dos sentidos e que são inevitavelmente esquecidos ou não acessados pelo enunciador. Segundo Pêcheux (1983 [1997]), a Análise de Discurso de linha francesa reflete sobre a materialidade da linguagem e da história, de modo a destacar as regiões de equívoco ou de aparente contradição, em que se ligam, materialmente, o inconsciente e a ideologia. Por ocasião da análise dos dados, alguns equívocos ou contradições, ideologicamente determinados, serão destacados.

\section{VISÕES DE LEITURA}

A visão estruturalista entende o processo de leitura como decodificação dos sentidos previamente codificados no texto e que devem ser decifrados de forma linear, por meio da combinação de sons, palavras, frases, parágrafos e assim por diante, como se um texto fosse um quebra-cabeça à espera de ser montado pelo leitor que deve encontrar e combinar as peças certas. Em suma, dentro dessa concepção, o texto é o detentor dos sentidos que devem ser decodificados pelo leitor. Segundo Coracini (2001, p. 143) "na visão estruturalista da leitura, ler significa atribuir sentido a algo que já está lá de forma imanente, que já tem sentido literal, independente do sujeito".

Sobre a concepção de sujeito e de linguagem que fundamentam a perspectiva estruturalista de leitura, observa-se que o sujeito-leitor é visto como um ser unívoco, dotado de mente e de razão, capaz de buscar e encontrar o controle de si, do seu dizer e dos outros, através da tomada de consciência de si e dos fenômenos que o cercam (CORACINI, 2000). A língua, por sua vez, de acordo com a referida autora, é definida como conjunto de estruturas, frases, vocábulos, sons, cujo sentido é estável, imanente e transparente.

A perspectiva interacionista de leitura propõe a existência de um leitor, separado do autor e do texto, e que deve contribuir, ativamente, para a construção dos sentidos. Pressupõe-se que os significados oriundos do texto devem ser construídos, através de uma constante interação entre o leitor, o autor, o texto e a negociação e ativação de conhecimentos prévios do leitor. Segundo Coracini 
(2001, p.143), "ler é construir sentido, a partir das peças e regras definidas por outro sujeito, que acredita respeitar o núcleo de sentido (presente no texto) em torno do qual é permitido ao leitor construir variações, desde que estas não contradigam o texto".

Valendo-nos da citação acima, observa-se que, embora na perspectiva interacionista o papel do aluno-leitor seja mais ativo, no que tange à negociação e atribuição de sentidos, o texto ainda é tido como o núcleo detentor dos sentidos legítimos ou autorizados pelo autor, e que devem ser perseguidos pelo leitor, através das pistas deixadas no texto ou dos marcadores textuais e argumentativos, por exemplo. Nesse sentido, o papel do professor, nas aulas e atividades de leitura, é conduzir a leitura e discussão dos textos, de modo a possibilitar o desvendamento das pistas deixadas pelo autor e que levariam à interpretação 'correta' ou mais autorizada do texto.

A ideia de leitura como processo cognitivo ou mental também embasa a perspectiva interacionista e os procedimentos sugeridos no processo de leitura, tendo em vista que, de acordo com Leffa (1996), dentro da visão interacionista de leitura, o leitor deve acionar conhecimentos prévios, ao ler um texto, já que sem o acionamento de experiências passadas, a compreensão não seria possível.

Com base nas considerações anteriores, observa-se que a linguagem ainda é vista, na perspectiva interacionista, como algo transparente e passível de instrumentalização, uma vez que o texto serviria para acionar e construir esquemas mentais, isto é, pacotes de conhecimentos estruturados e estabilizados, adquiridos socialmente. Dito de outro modo, a língua é vista como um instrumento que pode ser manipulado e controlado pelo sujeito-leitor, de acordo com seus objetivos de leitura, à medida que este aprende a desvendar o texto, através da aplicação de estratégias de leitura metacognitivas ${ }^{1}$.

Em contrapartida, a perspectiva discursiva, perpassada pelo desconstrutivismo, entende a linguagem como um contínuo processo de produção de sentidos ou de efeitos de sentido, pois, de acordo com Derrida (1981 apud Arrojo, 1992), as palavras sempre carregam outros significados que elas colocam em movimento, apesar de nossos esforços para fechar o significado. Daí o distanciamento desta perspectiva em relação à visão estruturalista, segundo a qual cada significante corresponderia a um significado mais ou menos fixo ou socialmente convencionado e compartilhado.

Na visão discursiva de leitura, segundo Coracini (2001, p.141), "ler pressupõe um sujeito que produz sentidos, envolvendo-se, dizendo-se, significando-se,

1 As estratégias de leitura serão retomadas na seção posterior, por ocasião da análise das propostas contidas nos documentos analisados. 
identificando-se". Assim sendo, o processo de leitura, nesta visão, vai além da interação entre o conhecimento de mundo do leitor, o sentido imaginariamente intencionado pelo autor e as pistas deixadas no texto, já que se constitui em um processo de ressignificação constante, diretamente atrelado à posição discursiva, portanto, ideológica, do leitor e do momento socio-histórico vivenciado.

Balizando-nos pela perspectiva discursiva, não podemos perder de vista a relação indissociável entre discurso, sujeito e ideologia, que viabiliza a deriva de sentidos. Discursivamente, de acordo com Orlandi (1997), a ideologia é uma necessidade da relação da língua com a história, na constituição dos sujeitos e dos sentidos. Assim sendo, podemos afirmar que é a ideologia que determina e atribuiu determinados sentidos ao que é dito.

Passemos à análise de trechos dos documentos anteriormente mencionados, à luz das visões de leitura arroladas e da perspectiva discursiva.

\section{ANÁLISE DOS DOCUMENTOS OFICIAIS E DO MATERIAL APOSTILADO}

De acordo com os Parâmetros Curriculares Nacionais de Língua Estrangeira do Ensino Fundamental (PCN-LE, 1998), o trabalho desenvolvido em sala de aula de LE deve enfatizar, dentro das habilidades comunicativas, o processo da compreensão escrita e oral "que envolve fatores relativos ao processamento da informação, cognitivos e sociais" (PCN-LE, 1998, p.89). Nesse prisma, as tarefas desenvolvidas devem funcionar como experiências construtoras da aprendizagem, uma vez que integram as dimensões interacional, lingüística e cognitiva da aprendizagem de LE (PCN-LE, 1998, p.88).

Com base nos trechos destacados anteriormente, observa-se uma orientação sociointeracionista, perpassada pela visão cognitivista, para efeito de formulação das propostas e procedimentos didáticos que compõem o referido documento. O trecho a seguir aponta para as visões ou orientações teóricas que deveriam fundamentar a aprendizagem de LE: "Assim, os processos cognitivos são gerados por meio da interação entre um aluno e um participante de uma prática social, que é um parceiro mais competente, para resolver tarefas de construção de significado/ conhecimento com as quais esses participantes se depararem" (PCN-LE, 1998, p.57-58).

Nota-se, partindo da citação destacada acima, que o documento pressupõe uma relação assimétrica entre os participantes de uma prática social 
e/ou interativa, sobretudo nas aulas de LE, provavelmente em função do variado nível de conhecimento linguístico dos alunos e, inclusive, da (não) competência comunicativa do professor de LE. Assim sendo, propor uma prática colaborativa, em sala de aula de LE, estabelecendo funções específicas para cada participante do grupo, solucionaria alguns possíveis problemas ocasionados pela diferença de conhecimento linguístico entre os alunos e pela heterogeneidade do grupo. Vale ressaltar que a prática colaborativa também encontra respaldo e se justifica pela visão interacionista.

Apesar de ter sido desenvolvido uma década após os PCN-LE do Ensino Fundamental, abordado anteriormente, a Proposta Curricular dos Ensinos Fundamental e Médio do Estado de São Paulo, e o Caderno do Professor, destinado ao ensino de inglês do ensino Médio, ambos publicados em 2008, partem da mesma orientação teórica dos PCN-LE (1998), mantendo, como foco principal, a formação da competência de leitura e de escrita, mesmo já prevendo a realização de atividades de produção oral, conforme destacado abaixo:

Não se trata mais de privilegiar a gramática ou as funções comunicativas, mas de promover o conhecimento e o reconhecimento de si e do outro, traduzido em diferentes formas de interpretação do mundo, concretizadas nas atividades de produção oral e escrita, desenvolvidas em cada uma das etapas da escolarização. (SEE a, 2008, p.43)

O caráter sociointeracionista da Proposta Curricular também se materializa no seguinte trecho, no qual se destaca o objetivo primordial de tal documento: "Fruto do trabalho coletivo, de caráter interdisciplinar, a Proposta procura estabelecer elos entre os conhecimentos culturais socializados pela escola e as indicações de procedimentos organizados didaticamente" (SEE, 2008 b, p. 6).

De modo geral, os trechos salientados anteriormente colocam o discurso da união social em funcionamento, além de ratificarem a representação sociohiostoricamente construída da escola como principal disseminadora do conhecimento, cuja função, dentre outras, seria harmonizar e possibilitar a vida em sociedade.

A natureza interdisciplinar dos documentos e das atividades neles sugeridas apontam para uma tentativa de atender à demanda pedagógica atual, isto é, o macrodiscurso político-educacional vigente, que além de direcionar e prescrever a prática pedagógica interdisciplinar, também fornece diretrizes para a elaboração de exames nacionais como o ENEM. 
Voltando-nos, mais especificamente, para O Caderno do Professor de LE do Ensino Médio (SEE, 2008 b) ${ }^{2}$, observamos que se trata de um material que não apenas fornece parâmetros e subsídios para a prática docente, mas que se preocupa em fornecer um roteiro detalhado de situações de aprendizagem, incluindo o tempo previsto de aula, conteúdos e temas, competências desenvolvidas, estratégias de ensino, recursos utilizados e o tipo de avaliação a ser conduzida pelo professor. É significativo ressaltarmos que dentre as disciplinas oferecidas nos ensinos fundamental e médio, as disciplinas de línguas estrangeiras modernas foram as últimas a receberem e adotarem materiais didáticos para orientar o fazer docente.

Cada caderno apresenta propostas de atividades que partem de um tema organizador como "Cinema e Preconceito", e busca explorar um gênero específico como o gênero carta, por exemplo. A atividade escrita é realizada após a leitura e discussão de textos dentro do tema central, que visa a concretizar o conhecimento e as competências anteriormente trabalhados.

Em consonância com os objetivos dispostos nos PCN-LE (1998), o objetivo maior das orientações que compõem o Caderno do Professor de inglês é

\footnotetext{
[...] fazer com que nossos alunos, ao entrarem em contato com textos da língua inglesa, ampliem seus conhecimentos sobre outras culturas e comunidades, sobre a própria língua inglesa e sobre si mesmos, desenvolvendo habilidades de pensamento mais complexas em uma perspectiva pluricultural (SEE, 2008 b).
}

Em um estudo anterior (CAVALLARI, 2011, p. 5), já havia destacado que há um aspecto comum que deveria orientar a prática pedagógica: a ênfase nos aspectos socioculturais, uma vez que a maioria dos objetivos dispostos nos PCN-LE (1998) "destaca a importância de explorar o componente cultural presente no processo de ensino e aprendizagem de língua estrangeira".

A formação de um cidadão do mundo, através da disciplina de língua inglesa ou do contato com uma língua global e hegemônica, também é enfatizada pelos PCN-LE (1998) que pregam um maior entendimento de um mundo plural e do próprio papel do aluno como cidadão do mundo (PCN-LE, 1998, p.67).

Apesar de adotar uma orientação interacionista, propondo, nas atividades de leitura, "inferência de informações, construção de opiniões e construção de relações entre o texto lido e atitudes pessoais" (SEE, 2008 b, p.8), em alguns trechos do material analisado, destacam-se orientações de cunho estruturalista e, até mesmo, behaviorista, como no excerto a seguir:

2 Para realização deste estudo, nos pautaremos no Caderno do Professor de inglês, da segunda série do ensino médio, a ser trabalhado no terceiro bimestre (SEE, 2008 b). 
Tal proposta de trabalho [...] oferece um estudo sistematizado de estruturas gramaticais e vocabulário importantes para a formação de um leitor mais crítico, tanto no que se refere ao seu conhecimento de mundo e de tipos de textos quanto no que se refere ao seu conhecimento de língua.

Partindo da citação acima, observa-se que há uma (con)fusão de abordagens e perspectivas. Mais especificamente, a visão interacionista de leitura se funde à visão estruturalista, na qual a língua é vista como um quebra-cabeça, pronto para ser montado, manipulado e para significar por si só. Além disso, parece haver uma relação de causa e efeito preestabelecida, como se o conhecimento de estruturas gramaticais ou das partes do texto já possibilitasse uma leitura crítica, atrelada ao conhecimento de mundo do leitor.

Ao destacar a metodologia e estratégias adotadas pelo professor, no ensino médio, o referido material afirma que:

O processo espiralado continua: o vocabulário continua a ser ampliado em Situações de Aprendizagem que demandam seu uso mais automatizado, habilidades de leitura e escrita mais complexas são desenvolvidas, bem como estruturas gramaticais e seus usos em gêneros mais complexos são estudados de forma aprofundada (SEE, 2008 b, p.12)

Mais uma vez, as orientações anteriores enfatizam as partes que compõem um texto (vocabulário, estruturas gramaticais) e que possibilitariam abarcar o todo, ou seja, o entendimento de textos e gêneros mais complexos. Essas orientações nos parecem mais condizentes com um processo linear e de dificuldade gradual de ensino, e não com um processo espiralado, como sugere o material abordado. Também é possível observar uma tentativa de automatização e aplicação do conhecimento lexical que viabilizaria o desenvolvimento das habilidades de leitura e escrita. Tal concepção, por sua vez, nos remete à visão behaviorista, que enfatiza exercícios de repetição e de memorização e que, de acordo com os documentos oficiais, deve ser suplantada ou substituída pela visão interacionista.

Essas contradições, longe de apontar culpados pelas incoerências pedagógicas, nos permitem vislumbrar a heterogeneidade de vozes, metodologias, abordagens e discursos que nos constituem e que, pelo fato de sermos sujeitos assujeitados à linguagem e ao seu funcionamento singular, não conseguiremos jamais neutralizar ou silenciar.

As tarefas propostas no Caderno do Professor (SEE, 2008 b, p. 8-9), através de textos escritos em língua inglesa (LI), tais como: "levantamento de hipótese e sua confirmação; observação de palavras cognatas; ênfase na leitura rápida para a 
apreensão do sentido geral de um texto e localização de informações específicas (skimming e scanning); interpretação de informações e relações a partir da leitura, dentre outras, são algumas das estratégias de leitura metagonitivas elaboradas e praticadas, com base na visão interacionista de leitura e nos processos cognitivos. Essas estratégias revolucionaram o processo de leitura em LE, há algumas décadas, e, ainda hoje, fundamentam as aulas e atividades propostas nos cursos de inglês instrumental para leitura, nas quais uma série de estratégias de leitura é apresentada aos alunos, para que estes se tornem leitores capazes de recuperar o significado do texto, o que sugere uma única leitura autorizada de cada texto. Leffa (1996) salienta a importância da metacognição no processo de leitura, cujas principais áreas de concentração são a identificação das estratégias usadas pelo leitor e o papel desempenhado por essas estratégias na compreensão da leitura. Nas palavras do autor (1996, p.46), "a metacognição na leitura trata do problema do monitoramento da compreensão feito pelo próprio leitor durante o ato da leitura".

Com base nas considerações anteriores, observa-se que, na visão interacionista de leitura, o bom leitor é aquele que tem consciência das estratégias que utiliza e que consegue aplicá-las corretamente, de acordo com a tarefa desenvolvida no processo de leitura. Essa tomada de consciência das estratégias utilizadas pelos 'bons leitores' também é destacada pelos PCN-LE (1998, p.91), ao prescreverem o modo como a compreensão escrita deve ser trabalhada pelo professor: (...) "o professor deve se balizar pelos conhecimentos que o aluno tem de sua língua materna e do mundo. Por exemplo, numa atividade de leitura, o professor deve fazer com que o aluno tome consciência (grifo meu) do que já sabe ao explorar itens lexicais cognatos". Essas afirmações pressupõem o controle total dos agentes envolvidos no processo de leitura, principalmente por parte do professor. Talvez por isso o professor se angustie tanto diante de situações contingenciais, que não estavam previstas no 'roteiro de aprendizagem', sugerido no Caderno do Professor de inglês (SEE, 2008 b).

Retomando o caderno do professor de inglês (SEE, 2008 b, p 9), encontramos a descrição das quatro situações de aprendizagem que devem ser seguidas e respeitadas, para que os conteúdos do bimestre sejam ministrados de forma efetiva. São elas:

Em um primeiro momento, os alunos se aproximam do tema a ser estudado, mobilizando os conhecimentos prévios sobre o assunto, sobre os diferentes tipos de texto e sobre a língua inglesa utilizada para falar sobre propaganda ${ }^{3}$. Em um segundo momento, os alunos desenvolvem habilidades específicas para a leitura dos textos propostos,

3 No Caderno do Professor analisado, o gênero propaganda era central. 
ressignificando novos conhecimentos ou ampliando conhecimentos previamente adquiridos sobre a língua, sobre os diferentes tipos de textos utilizados e sobre o mundo. Em um terceiro momento, os alunos vão personalizar os conhecimentos mobilizados e adquiridos nas etapas anteriores da Situação de Aprendizagem para ampliá-los e usá-los em outros contextos, para compreensão de novos textos, por exemplo. $\mathrm{Na}$ última situação de aprendizagem, os alunos produzirão um texto, no qual os conhecimentos adquiridos devem ser aplicados de forma personalizada.

As situações de aprendizagem destacadas anteriormente, em especial os dois primeiros momentos, reproduzem as estratégias de leitura, utilizadas pelos bons leitores, e descritas por Leffa (1996), com base nos estudos de Olshavsky (1978). Essas estratégias, de natureza metacognitiva, também parecem seguir uma sequência predeterminada e linear. São elas: inferência, levantamento de hipótese, substituir palavras por sinônimos, identificar-se pessoalmente com o texto, reler o que não entendeu, procurar fontes de informação adicional, pular as palavras desconhecidas, procurar visualizar o texto e propor conclusões pessoais. Dentro desta visão de leitura, o bom leitor é aquele que tem consciência das estratégias de leitura que utiliza, além de conseguir manipulá-las e aplicá-las, de acordo com os objetivos de leitura.

Ainda com base nas orientações retiradas do Caderno do Professor (SEE b, 2008), conclui-se que a aprendizagem se dá por etapas lineares, pré-determinadas, e com um crescente grau de dificuldade. Assim sendo, se uma das etapas iniciais falhar, as etapas seguintes ou mais complexas se tornam inviáveis. Com base na visão discursiva de leitura, acreditamos que o aluno leitor seja capaz de personalizar o conhecimento adquirido através do texto estudado, desde seu primeiro contato com ele e não apenas na última etapa, que prevê a produção textual, tal como sugere o Caderno do Professor. Além disso, é válido questionarmos se é possível

aplicar o conbecimento de forma personalizada, como descrito na última etapa da situação de aprendizagem, tendo em vista que a aplicação teórica ou de práticas pedagógicas sugere a retomada e automatização de estratégias e técnicas já prescritas e praticadas anteriormente e não a singularização do conhecimento transmitido na escola, via prática de leitura. A aplicação cega e automática de estratégias de leitura faz com que os alunos acabem internalizando uma única maneira de abordar o texto.

\section{CONSIDERAÇÕES FINAIS}

Sem perder de vista as contribuições da perspectiva interacionista para o processo de leitura, tanto em língua materna como em LE, defendemos que - para 
além desta perspectiva perpassada pelo cognitivismo, e que, até certo ponto, reduz o leitor a um receptor ou perseguidor dos sentidos autorizados pelo texto ou das marcas deixadas nele pelo autor - a adoção de uma visão discursiva, no processo de leitura, também se mostra significativa, pois permite explorar os componentes culturais e ideológicos que permeiam as aulas de LE, sobretudo os textos e temas trabalhos, já que lingua, cultura e ideologia se constituem mutuamente. Nesse caso, não se trata de desqualificar ou abandonar os procedimentos sugeridos pela visão interacionista de leitura, mas de ir além deles, ao possibilitarmos, enquanto professores, a singularização e a desconstrução dos conhecimentos disseminados na/pela escola e pelos textos que são adotados nas disciplinas e perpetuados no material de apoio.

Faz-se necessário, no entanto, levarmos em conta as adversidades vivenciadas no contexto escolar, em especial da rede pública, dentre elas: a falta de competência comunicativa por parte do professor de LI, o que impossibilitaria ou pelo menos dificultaria o desenvolvimento de um trabalho com textos em inglês, pelo viés interacionista. Consequentemente, as aulas de LI limitar-se-iam ao exaustivo estudo de estruturas gramaticais descontextualizadas e distantes da interação, ou ao uso de textos como pretexto para o ensino da gramática pela gramática, sem vistas à comunicação ou transmissão de ideias e conhecimentos. Nesse cenário, a adoção de práticas pedagógicas de natureza interacionista, como propõem os documentos analisados, representaria um grande avanço no processo de ensino e aprendizagem da escola regular.

Em última instância, enfatizamos a importância de problematizarmos e refletirmos sobre as visões de leitura, bem como as concepções de sujeito e de linguagem que subjazem à nossa prática pedagógica, atentando para os efeitos dessa prática na constituição e formação do aluno-leitor.

\section{REFERÊNCIAS BIBLIOGRÁFICAS}

ARROJO, R. (Org.) (1992) O signo desconstruído: implicações para a tradução, a leitura e o ensino. Campinas: Pontes.

BRASIL. Secretaria da Educação Fundamental. (1998) Parâmetros Curriculares Nacionais: terceiro e quarto ciclos do ensino fundamental: Língua Estrangeira. Brasília: MEC/SEF.

CAVALLARI, J.S. (2011). Vozes dissonantes: o que pregam os PCN e o que buscam os alunos de língua estrangeira. In Revista Estudos Linguísticos, v.40, GEL. (no prelo)

CORACINI, M.J. (Org.) (1995). O Jogo Discursivo na Aula de Leitura: Lingua Materna e Lingua Estrangeira. Campinas, SP: Pontes. 
CORACINI, M.J. (2000) Autonomia, Poder e Identidade em Sala de Aula. In Lingüística e Educação: Gramática, Discurso e Ensino. Terceira Margem Editora, p.175 - 197. (2001) Heterogeneidade e leitura na aula de língua materna. In CORACINI; PEREIRA (Orgs.) Discurso e Sociedade: Práticas em Análise do Discurso. Pelotas: EDUCAT, p. $137-154$.

LEFFA, V.J. (1996) Aspectos da Leitura. Porto Alegre, Sagra: DC Luzzatto.

ORLANDI, E.P. (1997) Nota ao leitor. In PÊCHEUX, M. O discurso: estrutura ou acontecimento. Trad. Eni Orlandi. Campinas, Pontes.

PÊCHEUX, M. (1983/1997). O discurso: estrutura ou acontecimento. Trad. Eni Orlandi. Campinas: Pontes.

SÃO PAULO. Secretaria Estadual da Educação. (2008 a) Proposta Curricular do Estado de São Paulo: Língua Estrangeira Moderna - Inglês. São Paulo: MEC/SEE.

SÃO PAULO. Secretaria Estadual da Educação. (2008 b) Caderno do professor: LEM - inglês, ensino médio - $2^{a}$ série, $3^{\circ}$ bimestre / Secretaria da Educação. São Paulo: SEE.

Recebido: 28/05/2011

Aceito: 25/04/2012 